

\section{CLIMATE CHANGES}

Throughout its history, Earth's climate has varied, reflecting the complex interactions and dependencies of the solar, oceanic, terrestrial, atmospheric, and living components that make up planet Earth's systems. For at least the last million years, our world has experienced cycles of warming and cooling that take approximately 100,000 years to complete. Over the course of each cycle, global average temperatures have fallen and then risen again by about $9^{\circ} \mathrm{F}\left(5^{\circ} \mathrm{C}\right)$, each time taking Earth into an ice age and then warming it again. This cycle is believed associated with regular changes in Earth's orbit that alter the intensity of solar energy the planet receives. Earth's climate has also been influenced on very long timescales by changes in ocean circulation that result from plate tectonic movements. Earth's climate has changed abruptly at times, sometimes as a result of slower natural processes such as shifts in ocean circulation, sometimes due to sudden events such as massive volcanic eruptions. Species and ecosystems have either adapted to these past climate variations or perished.

While global climate has been relatively stable over the last 10,000 years-the span of human civilization-regional variations in climate patterns have influenced human history in profound ways, playing an integral role in whether societies thrived or failed. We now know that the opposite is also true: human activities-burning fossil fuels and deforesting large areas of land, for instance-have had a profound influence on Earth's climate. In its 2007 Fourth Assessment, the Intergovernmental Panel on Climate Change (IPCC) stated that it had "very high confidence that the global average net effect of human activities since 1750 has been one of warming." The IPCC attributes humanity's global warming influence primarily to the increase in three key heat-trapping gases in the atmosphere: carbon dioxide, methane, and nitrous oxide. The U.S. Climate Change Science Program published findings in agreement with the IPCC report, stating that "studies to detect climate change and attribute its causes using patterns of observed temperature change in space and time show clear evidence of human influences on the climate system (due to changes in greenhouse gases, aerosols, and stratospheric ozone)."1

To protect fragile ecosystems and to build sustainable communities that are resilient to climate change-including extreme weather and climate events-a climate-literate citizenry is essential. This climate science literacy guide identifies the essential principles and fundamental concepts that individuals and communities should understand about Earth's climate system. Such understanding improves our ability to make decisions about activities that increase vulnerability to the impacts of climate change and to take precautionary steps in our lives and livelihoods that would reduce those vulnerabilities.

1. Temperature Trends in the Lower Atmosphere: Steps for Understanding and Reconciling Differences. Thomas R. Karl, Susan J. Hassol, Christopher D. Miller, and William L. Murray, editors, 2006. A Report by the Climate Change Science Program and the Subcommittee on Global Change Research, Washington, DC. 


\section{CLIMATE SCIENCE LITERACY IS AN} ONGOING PROCESS.

No single person is expected to understand every detail about all of the fundamental climate science literacy concepts. Full comprehension of these interconnected concepts will require a systems-thinking approach, meaning the ability to understand complex interconnections among all of the components of the climate system. Moreover, as climate science progresses and as efforts to educate the people about climate's influence on them and their influence on the climate system mature, public understanding will continue to grow.

Climate is an ideal interdisciplinary theme for lifelong learning about the scientific process and the ways in which humans affect and are affected by the Earth's systems. This rich topic can be approached at many levels, from comparing the daily weather with long-term records to exploring abstract representations of climate in computer models to examining how climate change impacts human and ecosystem health. Learners of all ages can use data from their own experiments, data collected by satellites and other observation systems, or records from a range of physical, chemical, biological, geographical, social, economic, and historical sources to explore the impacts of climate and potential adaptation and mitigation strategies.

\section{HOW DO WE KNOW WHAT IS SCIENTIFICALLY CORRECT?}

\section{The Peer Review Process}

Science is an on-going process of making observations and using evidence to test hypotheses. As new ideas are developed and new data are obtained, oftentimes enabled by new technologies, our understanding evolves. The scientific community uses a highly formalized version of peer review to validate research results and our understanding of their significance. Researchers describe their experiments, results, and interpretations in scientific manuscripts and submit them to a scientific journal that specializes in their field of science. Scientists who are experts in that field serve as "referees" for the journal: they read the manuscript carefully to judge the reliability of the research design and check that the interpretations are supported by the data. Based on the reviews, journal editors may accept or reject manuscripts or ask the authors to make revisions if the study has insufficient data or unsound interpretations. Through this process, only those concepts that have been described through well-documented research and subjected to the scrutiny of other experts in the field become published papers in science journals and accepted as current science knowledge. Although peer review does not guarantee that any particular published result is valid, it does provide a high assurance that the work has been carefully vetted for accuracy by informed experts prior to publication. The overwhelming majority of peer-reviewed papers about global climate change acknowledge that human activities are substantially contributing factors.

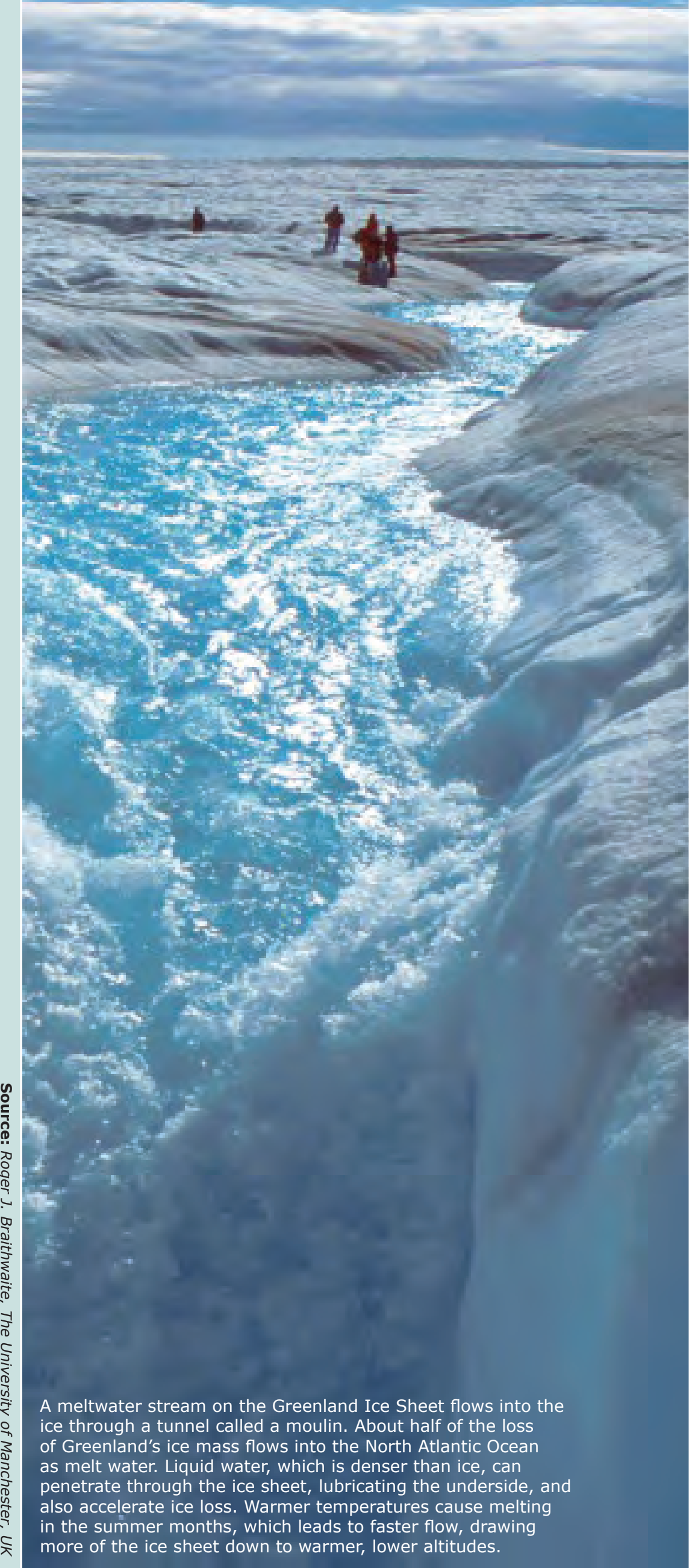




\section{CLIMATE DECISION:}

Humans can take actions to reduce climate change and its impacts.

A. Climate information can be used to reduce vulnerabilities or enhance the resilience of communities and ecosystems affected by climate change. Continuing to improve scientific understanding of the climate system and the quality of reports to policy and decision-makers is crucial.

B. Reducing human vulnerability to the impacts of climate change depends not only upon our ability to understand climate science, but also upon our ability to integrate that knowledge into human society. Decisions that involve Earth's climate must be made with an understanding of the complex interconnections among the physical and biological components of the Earth system as well as the consequences of such decisions on social, economic, and cultural systems.

C. The impacts of climate change may affect the security of nations. Reduced availability of water, food, and land can lead to competition and conflict among humans, potentially resulting in large groups of climate refugees.

D. Humans may be able to mitigate climate change or lessen its severity by reducing greenhouse gas concentrations through processes that move carbon out of the atmosphere or reduce greenhouse gas emissions.

$\mathrm{E}$. A combination of strategies is needed to reduce greenhouse gas emissions. The most immediate strategy is conservation of oil, gas, and coal, which we rely on as fuels for most of our transportation, heating, cooling, agriculture, and electricity. Short-term strategies involve switching from carbon-intensive to renewable energy sources, which also requires building new infrastructure for alternative energy sources. Long-term strategies involve innovative research and a fundamental change in the way humans use energy.

F. Humans can adapt to climate change by reducing their vulnerability to its impacts. Actions such as moving to higher ground to avoid rising sea levels, planting new crops that will thrive under new climate conditions, or using new building technologies represent adaptation strategies. Adaptation often requires financial investment in new or enhanced research, technology, and infrastructure.

G. Actions taken by individuals, communities, states, and countries all influence climate. Practices and policies followed in homes, schools, businesses, and governments can affect climate. Climate-related decisions made by one generation can provide opportunities as well as limit the range of possibilities open to the next generation. Steps toward reducing the impact of climate change may influence the present generation by providing other benefits such as improved public health infrastructure and sustainable built environments.

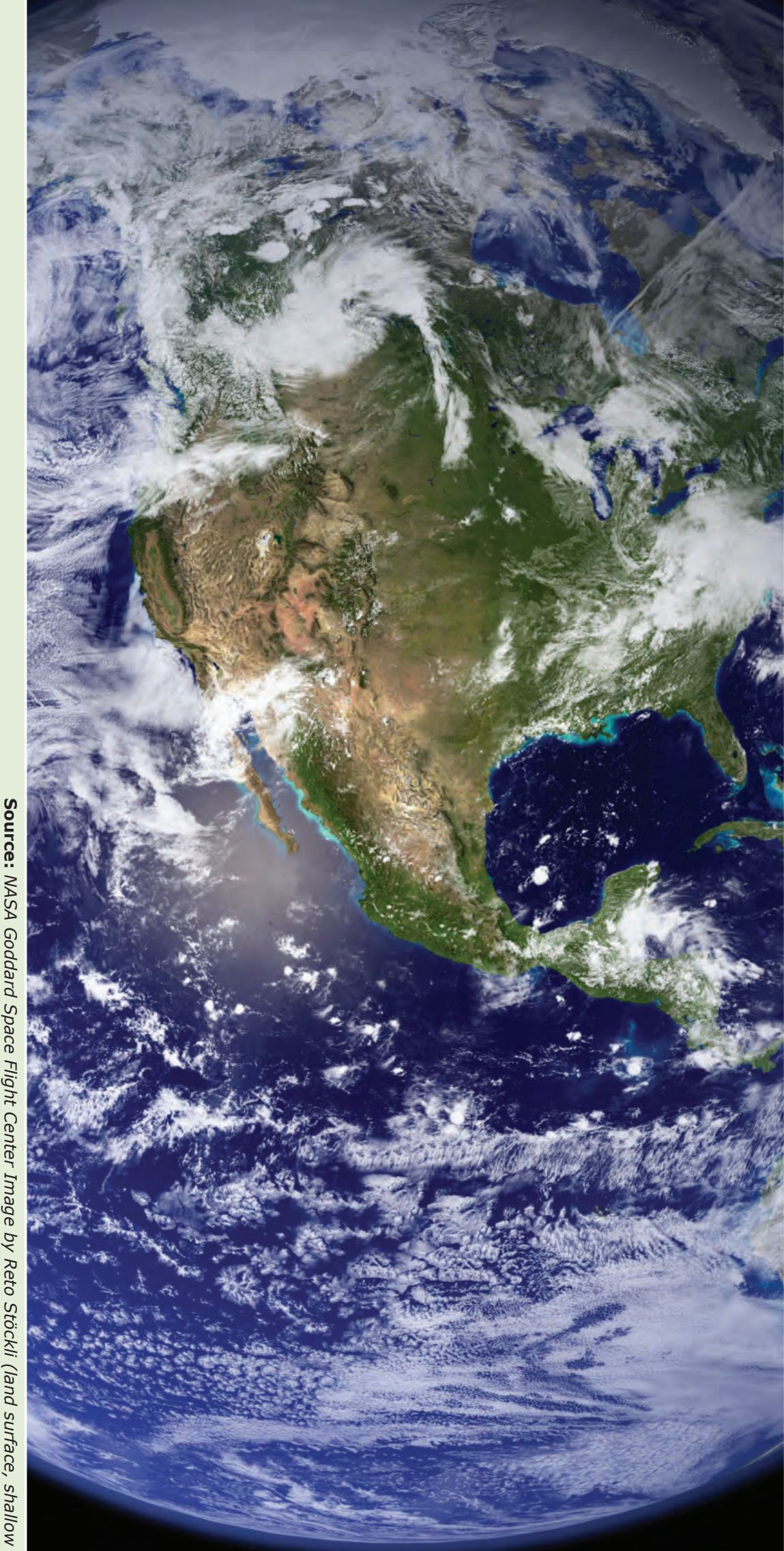

This spectacular "blue marble" image is the most detailed true-color image of the entire Earth to date. Using a collection of satellite-based observations, scientists and visualizers stitched together months of observations of the land surface, oceans, sea ice, and clouds into a seamless, true-color mosaic of every square kilometer (.386 square mile) of our planet. 
CLIMATE SCIENCE LITERACY IS AN UNDERSTANDING OF THE CLIMATE'S INFLUENCE ON YOU AND SOCIETY AND YOUR INFLUENCE ON CLIMATE

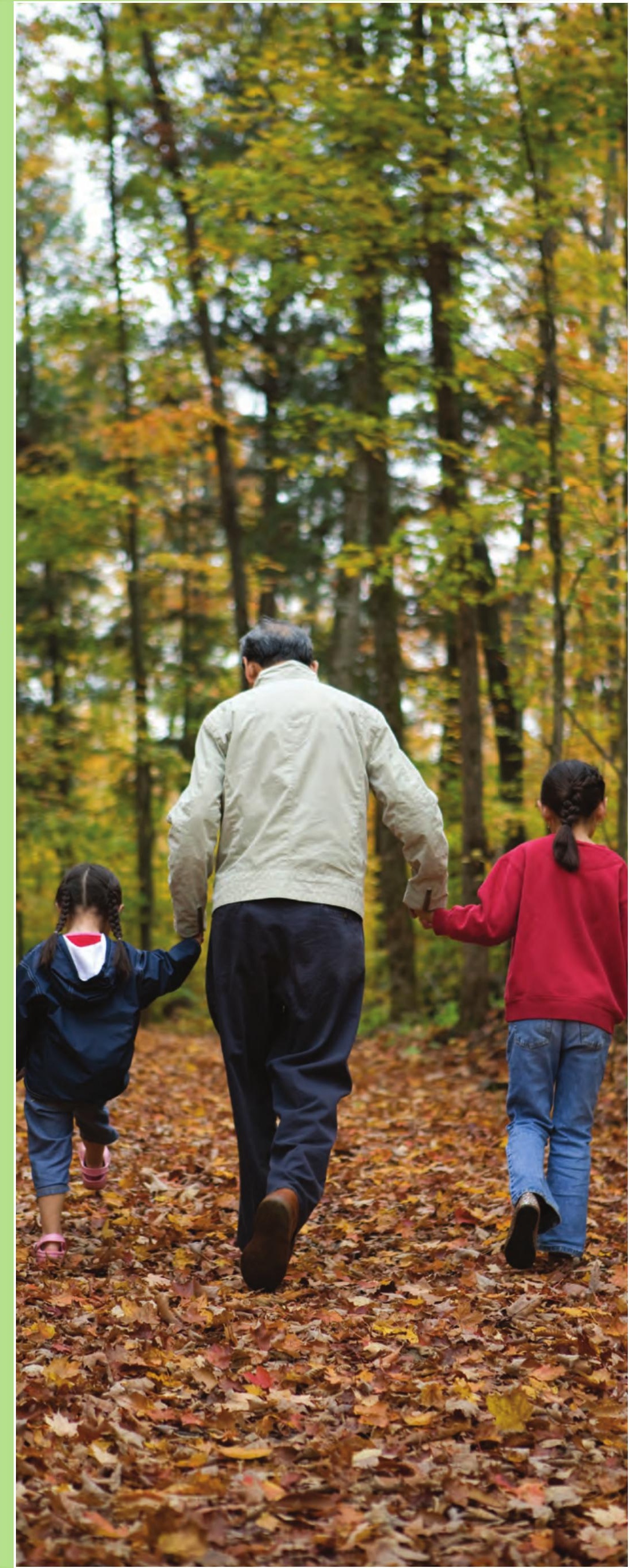




\section{CLIMATE LITERACY: The Essential Principles of Climate Science}

Each essential principle is supported by fundamental concepts comparable to those underlying the National Science Education Standards (NSES) and the American Association for the Advancement of Science (AAAS) Benchmarks for Science Literacy. 
A. Sunlight reaching the Earth can heat the land, ocean, and atmosphere. Some of that sunlight is reflected back to space by the surface, clouds, or ice. Much of the sunlight that reaches Earth is absorbed and warms the planet.

B. When Earth emits the same amount of energy as it absorbs, its energy budget is in balance, and its average temperature remains stable.

C. The tilt of Earth's axis relative to its orbit around the Sun results in predictable changes in the duration of daylight and the amount of sunlight received at any latitude throughout a year. These changes cause the annual cycle of seasons and associated temperature changes.
D. Gradual changes in Earth's rotation and orbit around the Sun change the intensity of sunlight received in our planet's polar and equatorial regions. For at least the last 1 million years, these changes occurred in 100,000 -year cycles that produced ice ages and the shorter warm periods between them.

E. A significant increase or decrease in the Sun's energy output would cause Earth to warm or cool. Satellite measurements taken over the past 30 years show that the Sun's energy output has changed only slightly and in both directions. These changes in the Sun's energy are thought to be too small to be the cause of the recent warming observed on Earth.

The greenhouse effect is a natural phenomenon whereby heat-trapping gases in the atmosphere, primarily water vapor, keep the Earth's surface warm. Human activities, primarily burning fossil fuels and changing land cover patterns, are increasing the concentrations of some of these gases, amplifying the natural greenhouse effect.

\section{NATURAL WARMING}

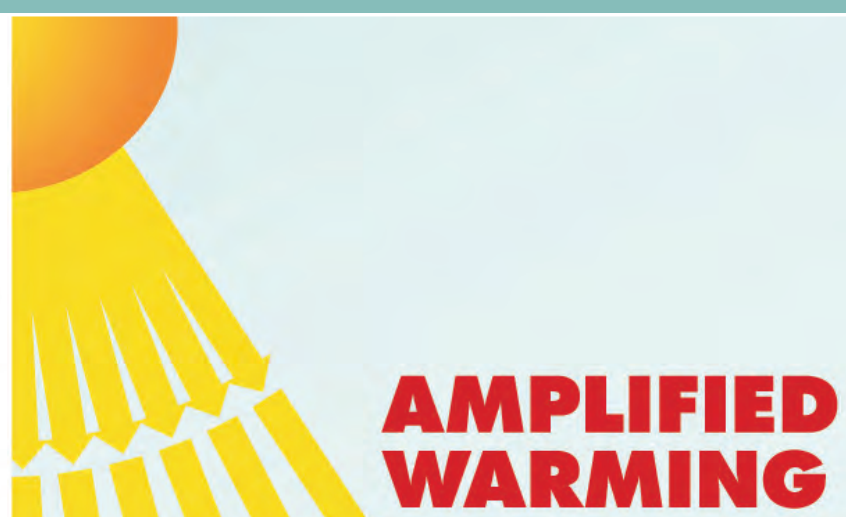




\section{CLIMATE IS REGULATED BY \\ COMPLEX INTERACTIONS \\ AMONG COMPONENTS OF \\ THE EARTH SYSTEM.}

A. Earth's climate is influenced by interactions involving the Sun, ocean, atmosphere, clouds, ice, land, and life. Climate varies by region as a result of local differences in these interactions.

B. Covering $70 \%$ of Earth's surface, the ocean exerts a major control on climate by dominating Earth's energy and water cycles. It has the capacity to absorb large amounts of solar energy. Heat and water vapor are redistributed globally through density-driven ocean currents and atmospheric circulation. Changes in ocean circulation caused by tectonic movements or large influxes of fresh water from melting polar ice can lead to significant and even abrupt changes in climate, both locally and on global scales.

C. The amount of solar energy absorbed or radiated by Earth is modulated by the atmosphere and depends on its composition. Greenhouse gasessuch as water vapor, carbon dioxide, and methaneoccur naturally in small amounts and absorb and release heat energy more efficiently than abundant atmospheric gases like nitrogen and oxygen. Small increases in carbon dioxide concentration have a large effect on the climate system.

D. The abundance of greenhouse gases in the atmosphere is controlled by biogeochemical cycles that continually move these components between their ocean, land, life, and atmosphere reservoirs. The abundance of carbon in the atmosphere is reduced through seafloor accumulation of marine sediments and accumulation of plant biomass and is increased through deforestation and the burning of fossil fuels as well as through other processes.

E. Airborne particulates, called "aerosols," have a complex effect on Earth's energy balance: they can cause both cooling, by reflecting incoming sunlight back out to space, and warming, by absorbing and releasing heat energy in the atmosphere. Small solid and liquid particles can be lofted into the atmosphere through a variety of natural and manmade processes, including volcanic eruptions, sea spray, forest fires, and emissions generated through human activities.

F. The interconnectedness of Earth's systems means that a significant change in any one component of the climate system can influence the equilibrium of the entire Earth system. Positive feedback loops can amplify these effects and trigger abrupt changes in the climate system. These complex interactions may result in climate change that is more rapid and on a larger scale than projected by current climate models.

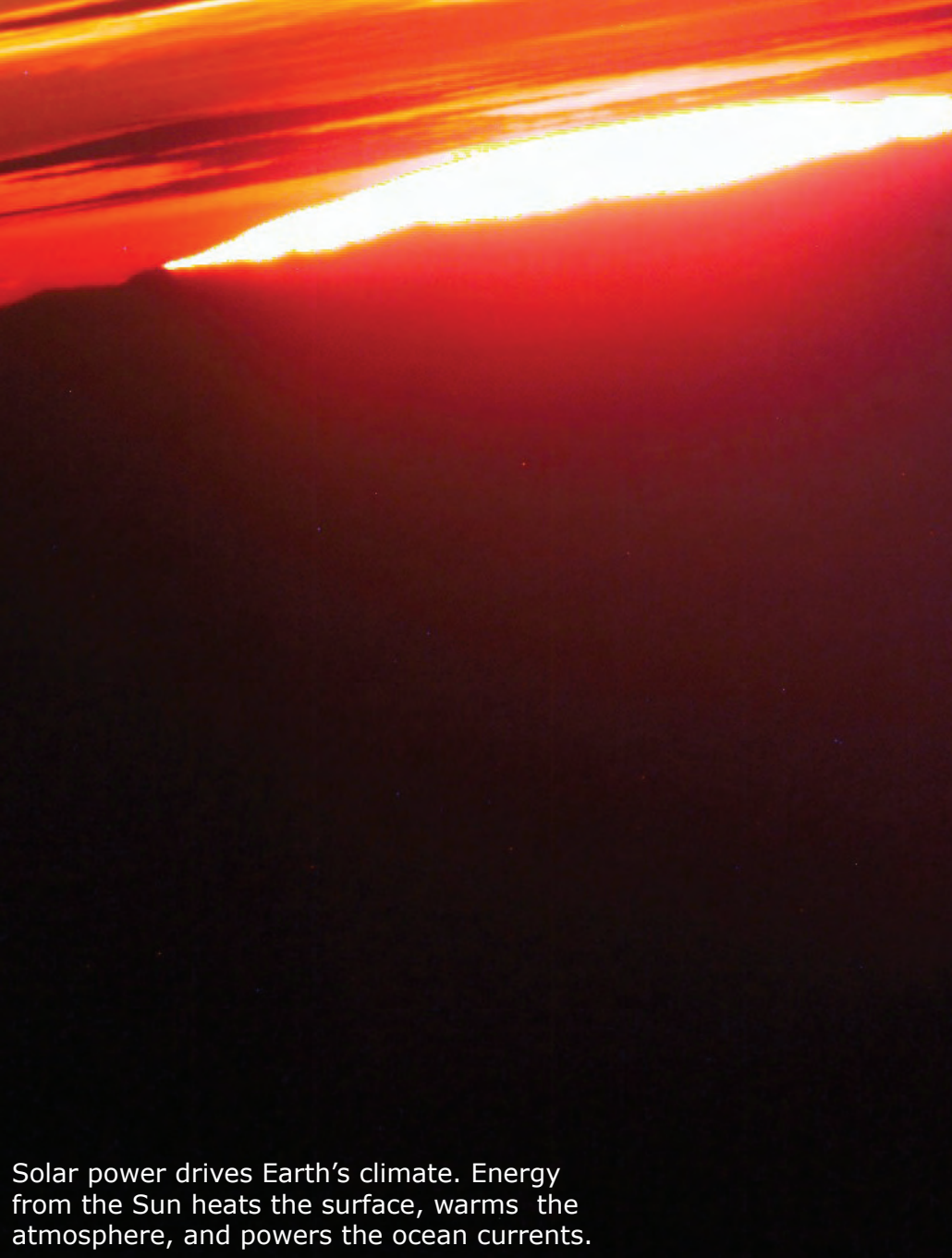




\section{LIFE ON EARTH DEPENDS \\ ON, IS SHAPED BY, AND AFFECTS CLIMATE.}

A. Individual organisms survive within specific ranges of temperature, precipitation, humidity, and sunlight. Organisms exposed to climate conditions outside their normal range must adapt or migrate, or they will perish.

B. The presence of small amounts of heat-trapping greenhouse gases in the atmosphere warms Earth's surface, resulting in a planet that sustains liquid water and life.

C. Changes in climate conditions can affect the health and function of ecosystems and the survival of entire species. The distribution patterns of fossils show evidence of gradual as well as abrupt extinctions related to climate change in the past.

D. A range of natural records shows that the last 10,000 years have been an unusually stable period in Earth's climate history. Modern human societies developed during this time. The agricultural, economic, and transportation systems we rely upon are vulnerable if the climate changes significantly.

E. Life-including microbes, plants, and animals and humans-is a major driver of the global carbon cycle and can influence global climate by modifying the chemical makeup of the atmosphere. The geologic record shows that life has significantly altered the atmosphere during Earth's history. 
A. Climate is determined by the long-term pattern of temperature and precipitation averages and extremes at a location. Climate descriptions can refer to areas that are local, regional, or global in extent. Climate can be described for different time intervals, such as decades, years, seasons, months, or specific dates of the year.

B. Climate is not the same thing as weather. Weather is the minute-by-minute variable condition of the atmosphere on a local scale. Climate is a conceptual description of an area's average weather conditions and the extent to which those conditions vary over long time intervals.

C. Climate change is a significant and persistent change in an area's average climate conditions or their extremes. Seasonal variations and multi-year cycles (for example, the EI Niño Southern Oscillation) that produce warm, cool, wet, or dry periods across different regions are a natural part of climate variability. They do not represent climate change.

D. Scientific observations indicate that global climate has changed in the past, is changing now, and will change in the future. The magnitude and direction of this change is not the same at all locations on Earth.

E. Based on evidence from tree rings, other natural records, and scientific observations made around the world, Earth's average temperature is now warmer than it has been for at least the past 1,300 years. Average temperatures have increased markedly in the past 50 years, especially in the North Polar Region.

F. Natural processes driving Earth's long-term climate variability do not explain the rapid climate change observed in recent decades. The only explanation that is consistent with all available evidence is that human impacts are playing an increasing role in climate change. Future changes in climate may be rapid compared to historical changes.

G. Natural processes that remove carbon dioxide from the atmosphere operate slowly when compared to the processes that are now adding it to the atmosphere. Thus, carbon dioxide introduced into the atmosphere today may remain there for a century or more. Other greenhouse gases, including some created by humans, may remain in the atmosphere for thousands of years.

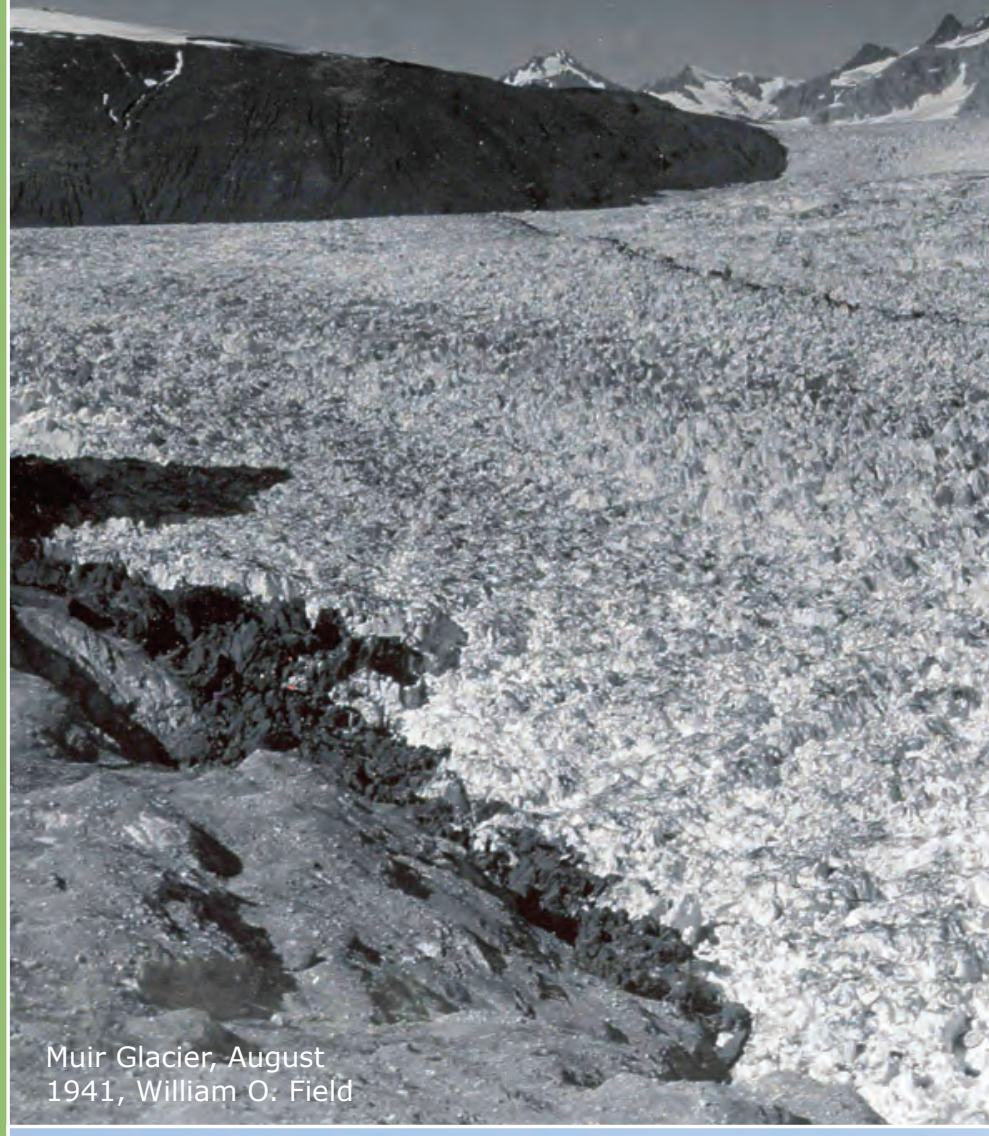

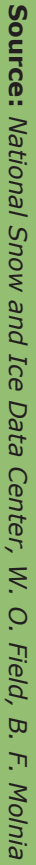




\section{OUR UNDERSTANDING OF THE CLIMATE SYSTEM IS IMPROVED THROUGH OBSERVATIONS, THEORETICAL STUDIES, AND MODELING.}

A. The components and processes of Earth's climate system are subject to the same physical laws as the rest of the Universe. Therefore, the behavior of the climate system can be understood and predicted through careful, systematic study.

B. Environmental observations are the foundation for understanding the climate system. From the bottom of the ocean to the surface of the Sun, instruments on weather stations, buoys, satellites, and other platforms collect climate data. To learn about past climates, scientists use natural records, such as tree rings, ice cores, and sedimentary layers. Historical observations, such as native knowledge and personal journals, also document past climate change.

C. Observations, experiments, and theory are used to construct and refine computer models that represent the climate system and make predictions about its future behavior. Results from these models lead to better understanding of the linkages between the atmosphere-ocean system and climate conditions and inspire more observations and experiments. Over time, this iterative process will result in more reliable projections of future climate conditions.
D. Our understanding of climate differs in important ways from our understanding of weather. Climate scientists' ability to predict climate patterns months, years, or decades into the future is constrained by different limitations than those faced by meteorologists in forecasting weather days to weeks into the future. 1

E. Scientists have conducted extensive research on the fundamental characteristics of the climate system and their understanding will continue to improve. Current climate change projections are reliable enough to help humans evaluate potential decisions and actions in response to climate change.

1. Based on "Climate Change: An Information Statement of the American Meteorological Society," 2007

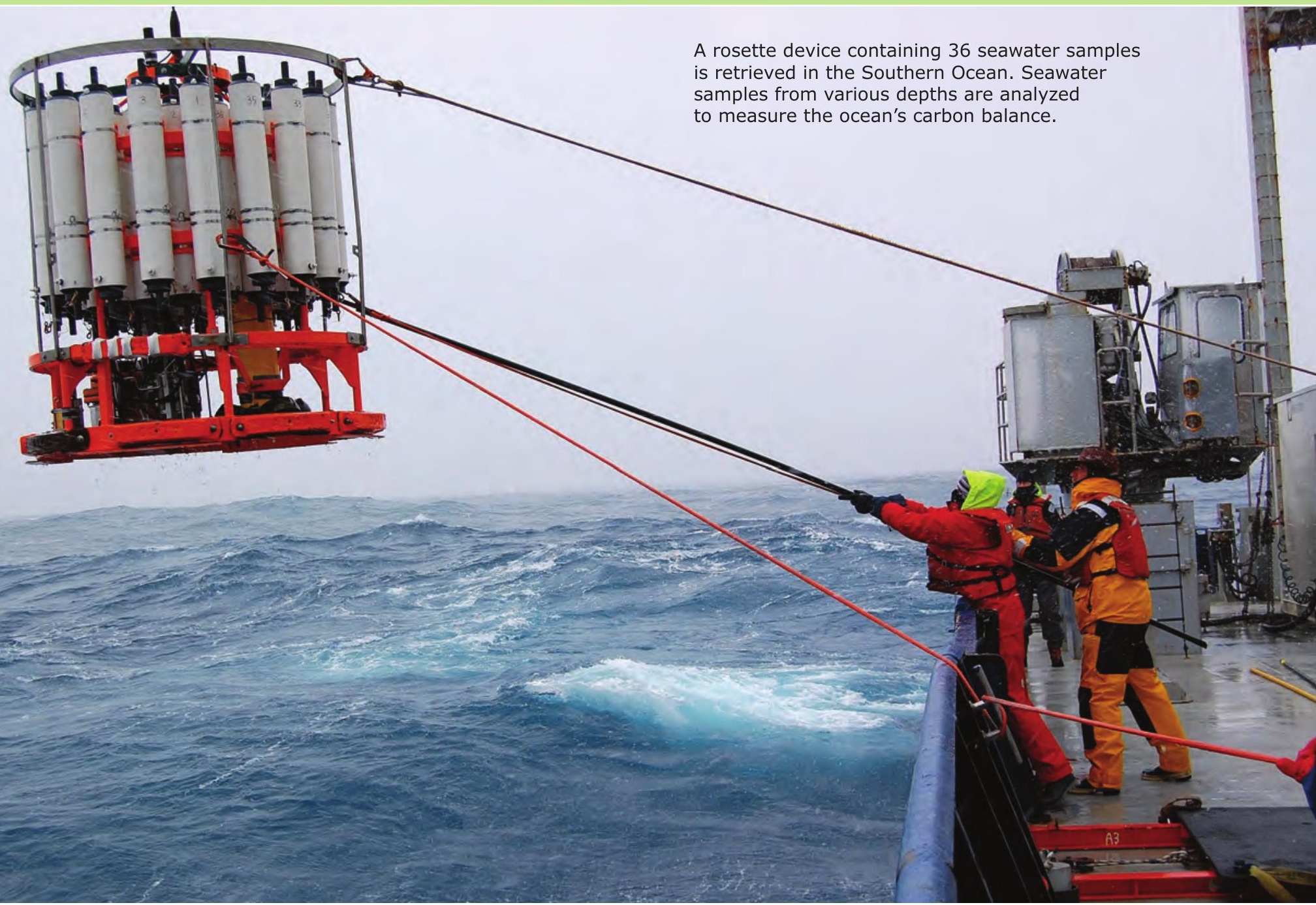


A. The overwhelming consensus of scientific studies on climate indicates that most of the observed increase in global average temperatures since the latter part of the 20th century is very likely due to human activities, primarily from increases in greenhouse gas concentrations resulting from the burning of fossil fuels. 2

B. Emissions from the widespread burning of fossil fuels since the start of the Industrial Revolution have increased the concentration of greenhouse gases in the atmosphere. Because these gases can remain in the atmosphere for hundreds of years before being removed by natural processes, their warming influence is projected to persist into the next century.

C. Human activities have affected the land, oceans, and atmosphere, and these changes have altered global climate patterns. Burning fossil fuels, releasing chemicals into the atmosphere, reducing the amount of forest cover, and rapid expansion of farming, development, and industrial activities are releasing carbon dioxide into the atmosphere and changing the balance of the climate system.

D. Growing evidence shows that changes in many physical and biological systems are linked to humancaused global warming. 3 Some changes resulting from human activities have decreased the capacity of the environment to support various species and have substantially reduced ecosystem biodiversity and ecological resilience.

E. Scientists and economists predict that there will be both positive and negative impacts from global climate change. If warming exceeds 2 to $3^{\circ} \mathrm{C}$ ( 3.6 to $5.4^{\circ} \mathrm{F}$ ) over the next century, the consequences of the negative impacts are likely to be much greater than the consequences of the positive impacts.

2. Based on IPCC, 2007: The Physical Science Basis: Contribution of Working Group I

3. Based on IPCC, 2007: Impacts, Adaptation and Vulnerability. Contribution of Working Group II 
A. Melting of ice sheets and glaciers, combined with the thermal expansion of seawater as the oceans warm, is causing sea level to rise. Seawater is beginning to move onto low-lying land and to contaminate coastal fresh water sources and beginning to submerge coastal facilities and barrier islands. Sea-level rise increases the risk of damage to homes and buildings from storm surges such as those that accompany hurricanes.

B. Climate plays an important role in the global distribution of freshwater resources. Changing precipitation patterns and temperature conditions will alter the distribution and availability of freshwater resources, reducing reliable access to water for many people and their crops. Winter snowpack and mountain glaciers that provide water for human use are declining as a result of global warming.

C. Incidents of extreme weather are projected to increase as a result of climate change. Many locations will see a substantial increase in the number of heat waves they experience per year and a likely decrease in episodes of severe cold. Precipitation events are expected to become less frequent but more intense in many areas, and droughts will be more frequent and severe in areas where average precipitation is projected to decrease. ${ }^{2}$

D. The chemistry of ocean water is changed by absorption of carbon dioxide from the atmosphere. Increasing carbon dioxide levels in the atmosphere is causing ocean water to become more acidic, threatening the survival of shell-building marine species and the entire food web of which they are a part.

E. Ecosystems on land and in the ocean have been and will continue to be disturbed by climate change. Animals, plants, bacteria, and viruses will migrate to new areas with favorable climate conditions. Infectious diseases and certain species will be able to invade areas that they did not previously inhabit.

F. Human health and mortality rates will be affected to different degrees in specific regions of the world as a result of climate change. Although cold-related deaths are predicted to decrease, other risks are predicted to rise. The incidence and geographical range of climate-sensitive infectious diseasessuch as malaria, dengue fever, and tick-borne diseases-will increase. Drought-reduced crop yields, degraded air and water quality, and increased hazards in coastal and low-lying areas will contribute to unhealthy conditions, particularly for the most vulnerable populations. 3

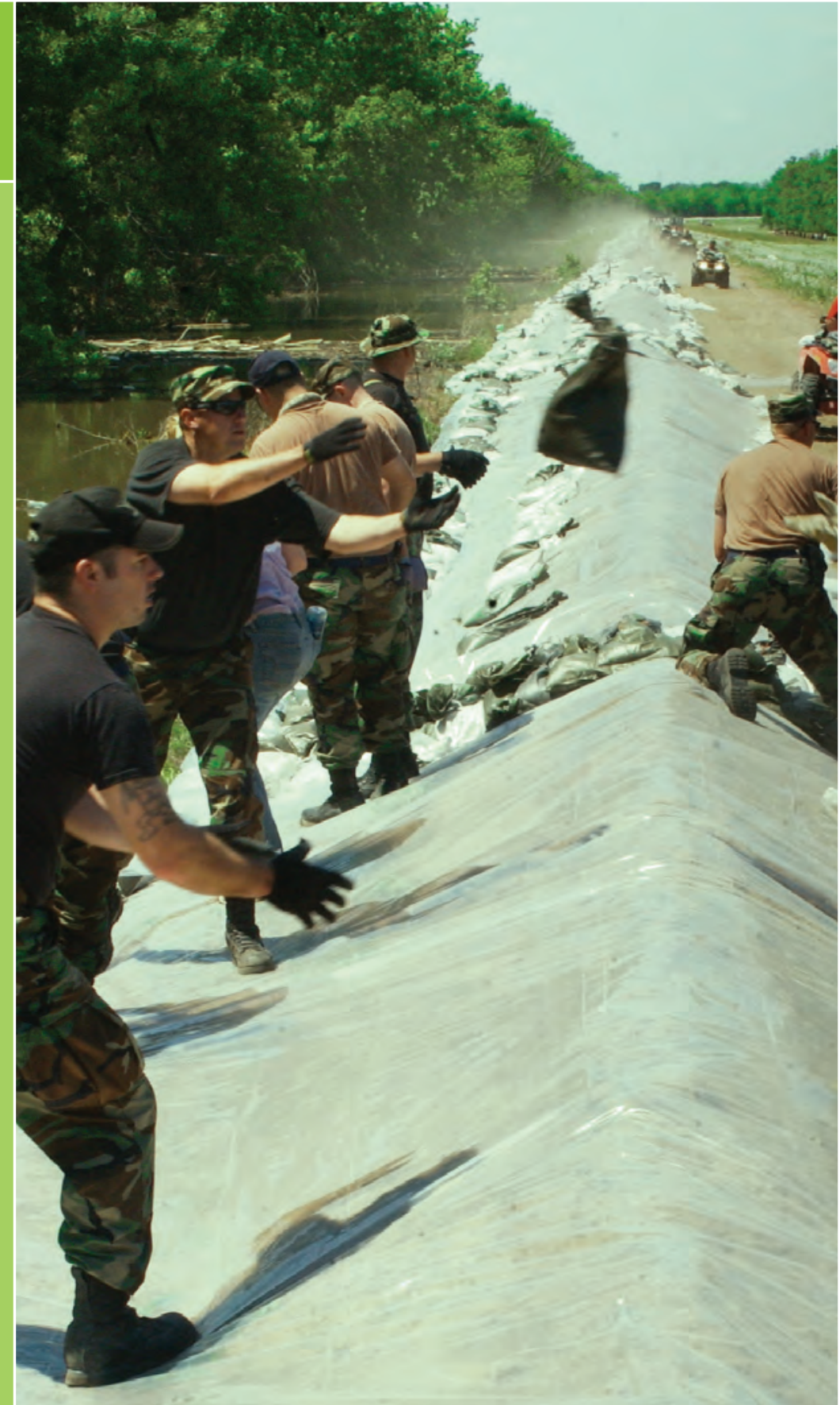

Iowa National Guard preparing to put sandbags in place on a levee in Kingston, Iowa, to protect roughly 50,000 acres of farmland threatened by flood waters. 


\section{KEY DEFINITIONS}

Weather The specific conditions of the atmosphere at a particular place and time, measured in terms of variables that include temperature, precipitation, cloudiness, humidity, air pressure, and wind.

Weather Forecast A prediction about the specific atmospheric conditions expected for a location in the short-term future (hours to days).

Climate The long-term average of conditions in the atmosphere, ocean, and ice sheets and sea ice described by statistics, such as means and extremes.

Climate Forecast A prediction about average or extreme climate conditions for a region in the long-term future (seasons to decades).

Climate Variability Natural changes in climate that fall within the normal range of extremes for a particular region, as measured by temperature, precipitation, and frequency of events. Drivers of climate variability include the EI Niño Southern Oscillation and other phenomena.

Climate Change A significant and persistent change in the mean state of the climate or its variability. Climate change occurs in response to changes in some aspect of Earth's environment: these include regular changes in Earth's orbit about the sun, re-arrangement of continents through plate tectonic motions, or anthropogenic modification of the atmosphere.

Global Warming The observed increase in average temperature near the Earth's surface and in the lowest layer of the atmosphere. In common usage, "global warming" often refers to the warming that has occurred as a result of increased emissions of greenhouse gases from human activities. Global warming is a type of climate change; it can also lead to other changes in climate conditions, such as changes in precipitation patterns.

Climate System The matter, energy, and processes involved in interactions among Earth's atmosphere, hydrosphere, cryosphere, lithosphere, biosphere, and Earth-Sun interactions.

Likely, Very Likely, Extremely Likely, Virtually Certain These terms are used by the Intergovernmental Panel on Climate Change (IPCC) to indicate how probable it is that a predicted outcome will occur in the climate system, according to expert judgment. A result that is deemed "likely" to occur has a greater than $66 \%$ probability of occurring. A "very likely" result has a greater than $90 \%$ probability. "Extremely likely" means greater than $95 \%$ probability, and "virtually certain" means greater than $99 \%$ probability.

Mitigation Human interventions to reduce the sources of greenhouse gases or enhance the sinks that remove them from the atmosphere.

Vulnerability The degree to which physical, biological, and socio-economic systems are susceptible to and unable to cope with adverse impacts of climate change. 2

Adaptation Initiatives and measures to reduce the vulnerability of natural and human systems against actual or expected climate change effects. 3

Fossil fuels Energy sources such as petroleum, coal, or natural gas, which are derived from living matter that existed during a previous geologic time period.

Feedback The process through which a system is controlled, changed, or modulated in response to its own output. Positive feedback results in amplification of the system output; negative feedback reduces the output of a system.

Carbon Cycle Circulation of carbon atoms through the Earth systems as a result of photosynthetic conversion of carbon dioxide into complex organic compounds by plants, which are consumed by other organisms, and return of the carbon to the atmosphere as carbon dioxide as a result of respiration, decay of organisms, and combustion of fossil fuels.

1. Temperature Trends in the Lower Atmosphere: Steps for Understanding and Reconciling Differences. Thomas R. Karl, Susan J. Hassol,

Christopher D. Miller, and William L. Murray, editors, 2006. A Report

by the Climate Change Science Program and the Subcommittee on Global Change Research, Washington, DC.

2. Based on IPCC, 2007: Impacts, Adaptation and Vulnerability. Contribution of Working Group II

3. Based on IPCC, 2007: Mitigation of Climate Change. Contribution of Working Group III 
Climate Literacy: The Essential Principles of Climate Science presents information that is deemed important for individuals and communities to know and understand about Earth's climate, impacts of climate change, and approaches to adaptation or mitigation. Principles in the guide can serve as discussion starters or launching points for scientific inquiry. The guide aims to promote greater climate science literacy by providing this educational framework of principles and concepts. The guide can also serve educators who teach climate science as a way to meet content standards in their science curricula.

Development of the guide began at a workshop sponsored by the National Oceanic and Atmospheric Administration (NOAA) and the American Association for the Advancement of Science (AAAS). Multiple science agencies, non-governmental organizations, and numerous individuals also contributed through extensive review and comment periods. Discussion at the National Science Foundation- and NOAA-sponsored Atmospheric Sciences and Climate Literacy workshop contributed substantially to the refinement of the document.

To download this guide and related documents, visit www.climatescience.gov.

\section{FURTHER INFORMATION}

For future revisions and changes to this document or to see documentation of the process used to develop this brochure, please visit www.climate.noaa.gov/education.

In addition, further information relating to climate literacy and climate resources can be found at:

- earthobservatory.nasa.gov

- www.epa.gov/climatechange

- http://nsdl.org

- www.education.noaa.gov
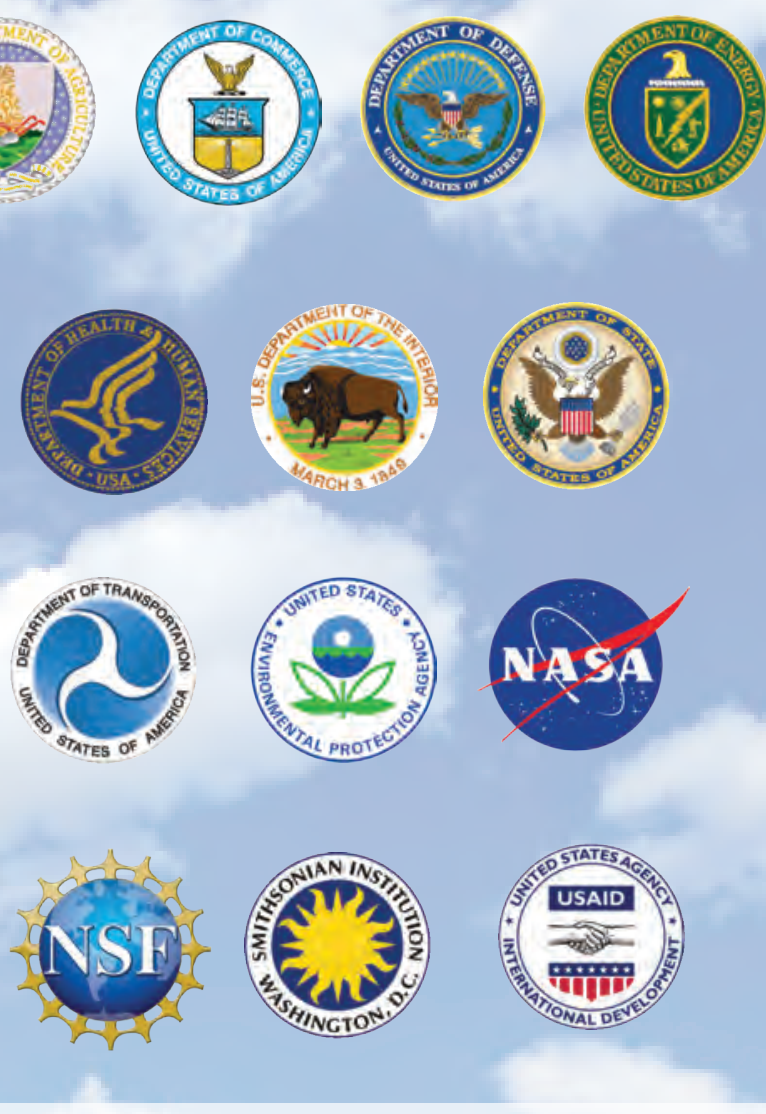

U.S. Global Change Research Program /

Climate Change Science Program

1717 Pennsylvania Avenue, NW Suire 250 Washington DC 20006 USA

+1.202.223.6262 (Voice) + 1.202.223.3065 (Fax)

http://www.climatescience.gov

climate.literacy@climatescience.gov

Current Science and Educational Partners:
American Association for the

Advancement of Science Project 2061

American Meteorological Society

Association of Science-Technology Centers

Bowman Global Change

Centers for Disease Control \& Prevention

Challenger Center for Space Science Education

Climate Literacy Network

College of Exploration

Cooperative Institute for Research in Environmental Sciences

Federation of Earth Science Information Partners

Lawrence Hall of Science, University of California, Berkeley

National Environmental Education Foundation
National Geographic Education Programs

National Institute of Standards \& Technology

National Oceanic and Atmospheric Administration

National Science Teachers Association

North American Association For Environmental Education

Sally Ride Science ${ }^{\mathrm{TM}}$

TERC Inc.

The GLOBE Program

The National Center for Atmospheric Research

University Corporation for Atmospheric Research

U.S. Geological Survey

U.S. Forest Service
For an up to date list of partners please refer to U.S Climate Change Science Program at http://www.climatescience.gov.
This document has been reviewed by the following Federal agencies. Any opinions, findings, and conclusions or recommendations expressed in this material are those of the author(s) and do not necessarily reflect the views of the National Science Foundation. 